\title{
Factors influencing knowledge sharing among layers: The case of Vietnam
}

\author{
Minh Tuyen Pham ${ }^{a^{*}}$
}

${ }^{a}$ The People's Court Bac Ninh, 46 Nguyen Gia Thieu Street, Suoi Hoa Ward, Bac Ninh City, Bac Ninh Province, Vietnam

CHRON I C L E

\begin{tabular}{l}
\hline Article history: \\
Received: August 82019 \\
Received in revised format: Sep- \\
tember 22 2019 \\
Accepted: October4, 2019 \\
Available online: \\
October 4, 2019 \\
\hline Keywords: \\
Knowledge \\
Knowledge sharing \\
Lawyers \\
PLS-SEM \\
Vietnam \\
\hline
\end{tabular}
\begin{abstract}
A B S T R A C T
Knowledge plays an important role for the development of any economy, any business especially within the law profession which requires profound knowledge. Knowledge sharing behaviors may improve the performance of the work. The proposed study of this paper is conducted among 398 lawyers in Vietnam to assess the factors affecting the knowledge sharing behavior of lawyers. After analyzing data based on Smart PLS software, the results show that the knowledge sharing behavior of lawyers in Vietnam contributes to their jobs except for the development process according to the planned behavioral theory. At the same time, the paper examines the mediating role of behavioral intent for the relationship between attitude and knowledge-sharing behavior which is statistically significant. However, the level of information use does not have any statistically significant role for the relationship between intentional behavior and knowledge sharing behavior of lawyers in Vietnam.
\end{abstract}

(C) 2020 by the authors; licensee Growing Science, Canada

\section{Introduction}

In a democratic judiciary in which human rights values are honored and the destination of the entire judicial system, with the mission of protecting justice and social equality, practice of the profession of lawyer is considered an important factor to evaluate the prestige and quality of judicial activities and an indispensable factor for the development of the country in the context of globalization and international economic integration. Lawyer is an independent judicial title, referring to those who are qualified to practice professionally as prescribed by law in order to provide legal advice, authorized representation, protection of legal rights and interests of individuals, organizations and the State to the Court and perform other legal services. The lawyers are simultaneously specialized practitioners of knowledge in different fields such as economics, health care, and technology (Ojo \& Grand, 2011). The lawyer has always confronted great challenges from updating knowledge as information is always unlimited, legal regimes and court decisions often change. Therefore, the profession of lawyer is unlike any other normal professions because in addition to the requirements on knowledge and professional qualifications, practicing as a lawyer must also comply with the code of professional ethics. This is a unique feature of the profession of Lawyer and this one impacts profoundly the practicing skills, especially the litigation skills of lawyers. Knowledge is an invaluable asset, which contains potential to contribute for organizational development. For that reason, knowledge sharing in each organization is paid attention by research in reality as well as in academic environment in order to find methods to encourage knowledge sharing, making good use of this core competitive advantage. Knowledge is the main power putting forward any economy. Knowledge is a combination of education and intelligence. Knowledge is composed of facts, information, descriptions, or skills acquired through experience or learning. In modern economy, knowledge is an important asset of each organization, especially companies that rely heavily on knowledgeable resources such as advisor, design, and in particular, law offices. Moreover, many previous studies (e.g. Kimiz, 2005) have revealed that it was necessary to share and transfer knowledge among individuals and units so that it could be brought into full play and create value and competitive advantages and make the organization develop sustainably. In spite of the importance of knowledge sharing, it is still a big challenge to introduce policies to encourage and promote knowledge sharing within each organization, especially law offices. Knowledge sharing within each unit is always barriered by lack of time, the fear of losing power and the fear of disadvantage.

* Corresponding author. Tel: +84 (0) 913519605

E-mail address: tuyenthuy63@gmail.com (M. T. Pham) 
Many studies on enhancing knowledge sharing behavior were carried out all over the world (Wei et al., 2012). In Vietnam, such studies were carried out by Bui (2014). Although many related studies were carried out, there was not much specific context in the area of lawyer. Therefore, this study was conducted to find out the factors that have impact on knowledge sharing behavior, evaluate how the factors affect knowledge sharing behavior, and test intermediary role of the intention variable and test the moderator role of information technology in the relationship between intention and knowledge sharing behavior, thereby proposing recommendations to enhance the knowledge sharing behavior of lawyers in law offices in the North of Vietnam.

In addition to the introduction, this paper includes: Overview of research, research methodology, research results and conclusions.

\section{Literature review}

\subsection{Knowledge}

Knowledge is justified true belief (Nonaka \& Takeuchi, 1995). Nonaka and Takeuchi (1996) also pointed out that knowledge was the process by which people proactively justify their personal beliefs to be true. Together with awareness evolution, information structure was formed to knowledge on two levels of understanding and independence from context. Perrot (2007) classified knowledge into two categories: (1) tacit knowledge in the human brain which is indefinable, and (2) explicit knowledge which can be expressed and captured easily.

In the opinion of Davenport and Prusak (1998): Knowledge was a collection of experience, values, information, and intelligent understanding that could help evaluate and gain new experience and information. Knowledge is created and applied in the minds of knowledgeable people. Within an organization, knowledge is contained not only in its documents and materials, but also in its procedures, processes, practices, and principles. People acquire knowledge from reality, and thus knowledge is understanding and learning of people. People sum up raw data and it becomes knowledge and is used specifically for a certain purpose to create value for people.

Kukko (2013) highlighted that knowledge in an organization is considered intellectual capital and exists in two main forms: tacit and explicit. Explicit knowledge is less dependent on people and can be systematized, measured, disseminated and stored, including information and communication skills and data transmission to others. Tacit knowledge is highly dependent on individuals and can be created by processing information combined with understanding and experience. According to Zawawi et al. (2011) most knowledge in organizations was tacit, as a result, it was difficult to connect with each other. As knowledge is always in each individual's brain, including many cognitive skills such as belief, images, intuition and other skills, not documents and materials so it is difficult to interpret or describe clearly.

\subsection{Knowledge Sharing}

Knowledge sharing was defined as exchange of knowledge (skills, experience and understanding) among individuals in an organization. Moreover, Gebretsadik et al. (2014) suggested that knowledge sharing could help employees share understanding and experience to help projects and plans finished quickly and cost-effectively. In addition, knowledge sharing is relevant to each individual in sharing information, ideas and experience with others. Knowledge sharing is based on the experience gained in working within and outside the organization. If knowledge is available throughout members, the organization will minimize duplicated decisions and solve problems faster. Effective knowledge sharing activities will help reuse knowledge of each individual and raise the knowledge to new a level (Chennamaneni et al., 2012)

Knowledge sharing is the process of transferring knowledge (especially tacit knowledge) from one person to another, on an individual level (exchanging) or collective level (training, coaching). This is an important stage in knowledge management cycle which ensures the success of knowledge management and thanks to knowledge sharing, tacit knowledge (accounting for the majority of knowledgeable resources) can be acquired and shared throughout the company. Promoting knowledge sharing is a big challenge for managers because employees often do not want to share their knowledge with others (due to the fear of losing power).

According to Senge (2007), knowledge sharing is a common activity for businesses to achieve their strategic goals. To share knowledge, people can use methods such as telling stories, sharing experience, discussing and lecturing new theories. Knowledge sharing is the process of repeating an idea or understanding of an individual or a group. Knowledge sharing is mandatory and disseminated in all departments and divisions within an organization. Knowledge sharing among individuals was the process of an individual's knowledge being transformed into a form that can be understood, acquired and applied by other individuals, contributing to the improvement of the ability to learn and cultivate professional knowledge of an organization (Ipe, 2003). Knowledge sharing helped convert an organization's knowledge into its economic values and competitive advantages (Hendriks, 1999).

Gottschalk et al. (2005) conducted a study on benefits of knowledge sharing through the usage of information technology in two law firms in Norway, the results showed that: Attitude of lawyers and their contributions to the organization were the 
most important factors making them willing to share knowledge. It was followed by lawyer's conception of rewards and income. Finally, lawyer's attitude towards commitment to the Bar Association was less influential on knowledge sharing behavior.

\subsection{Factors impact on Knowledge Sharing Behavior}

Many researches on the factors impacting on knowledge sharing behavior have been conducted, but mostly conceptual researches (Markus, 2001; Oliver \& Kandadi, 2006) or qualitative researches (Swart \& Kinnie, 2003). Several recent studies have conducted empirical research through survey questionnaires (Lee \& Choi, 2003). In spite of any form, studies provided a number of factors affecting the knowledge sharing behavior of individuals such as: Difficulties in sharing knowledge due to lack of tools and technology (Hlupic et al., 2002), motivation and encouragement of knowledge sharing, national culture, organizational culture, personal values (Lin \& Lee, 2004), accessibility to knowledgeable people in the organization (Bhatti et al., 2014).

This study examines the factors that have effect on knowledge sharing behavior of lawyers in law offices in the North of Vietnam based on the theory of planned behavior developed from the research by Ajzen \& Fishbein (2005). Therefore, factors affecting knowledge sharing behavior include attitudes, subjective norms, and perceived behavioral control, thereby forming behavioral intention and ultimately impacting on knowledge sharing behavior in reality.

\section{Research methodology}

The method of quantitative research was mainly used in this study. The research was conducted through two steps: preliminary research and official research. Preliminary research was conducted through qualitative methods with direct interview techniques abd group discussions used to examine research hypotheses and adjust the scale of knowledge sharing. The official research was conducted through surveying using online and direct survey questionnaires.

\subsection{Sample}

Research sample is the lawyers named in the Vietnamese lawyer directory (http://danhbaluatsu.net/danhba/). From the Vietnamese lawyer directory, we selected lawyers in the North of Vietnam, then used the random number selection technique on Excel to randomly select 600 lawyers in the directory. After that, we sent the questionnaire directly by mail and online questionnaire to 600 selected lawyers. After 3 months of data collection, we collected 492 questionnaires and conducted classification, checking information and entering data into the Excel software. After cleaning the data, 398 valid questionnaires were included in the analysis.

\subsection{Research model}

The research model is as follows:

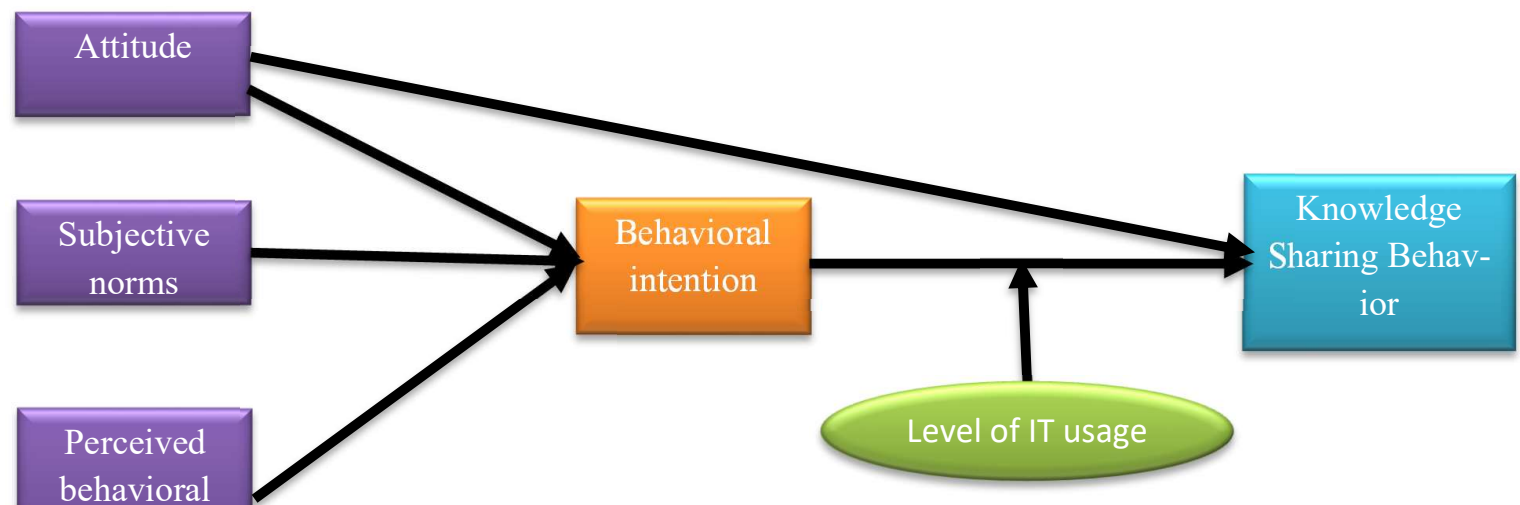

Fig 1. Research model

Attitude: means awareness of problem and the ability to participate in behavior formation. To measure attitude, we used 12 items measured using a 5-point Likert scale from totally disagree to totally agree, developed and adjusted from the study by Mafabi et al. (2017) and Asiegbu \& Iruka, (2012).

Subjective norms: means subjective point of views of lawyers in the North of Vietnam on knowledge sharing, measured by 6 items adjusted and developed from the study by Mafabi et al. (2017) on a 5-point Likert scale from totally disagree to totally agree. 
Perceived behavioral control: means a psychological state, an individual's perception of lawyers of ability and motivation to shape the intention of knowledge sharing. This variable is measured by 5 items developed and adjusted from the study by Mehrabi et al. (2013), Mafabi et al. (2017); on a 5-point Likert scale from totally disagree to totally agree.

Behavioral intention: means a state of being willing to make a certain decision and activity. In this paper, it is intention of knowledge sharing behavior of lawyers, measured on a 5-point Likert scale from totally disagree to totally agree through 6 items developed and supplemented from the study by Wu and Zhu (2012).

Knowledge sharing behavior: means activities of exchange, lecture, telling story of knowledge, experience, lessons by lawyers measured through 10 items on a 5-point Likert scale from totally disagree to totally agree. These scales are developed, supplemented and adjusted from the study by Wu and Zhu (2012), Mehrabi et al. (2013), Mafabi et al. (2017).

Level of information technology usage: means a variable moderating the impact of the behavioral intention to the knowledge sharing behavior of lawyers. For this factor, the level of using information technology devices to share knowledge is measured on a four-level scale including Never, Rarely, Occasionally, and Often, developed and inherited from the study by Wu and Zhu (2012).

Research hypotheses:

$\mathbf{H}_{1}$ : Attitude has a positive impact on Behavioral intention.

$\mathbf{H}_{2}$ : Subjective norms has a positive impact on Behavioral intention.

H3: Perceived behavioral control has a positive impact on Behavioral intention.

H4: Behavioral intention has a positive impact on Knowledge Sharing Behavior.

H5: Behavioral intention plays a mediate role on the relationship between Attitude and Knowledge Sharing Behavior.

H6: Level of IT usage plays a mediate role on the relationship between Behavioral intention and Knowledge Sharing Behavior.

\subsection{Analysis}

The data were analyzed using Smart PLS 3.0 software. Cronbach's Alpha: $>0.6$, Outer Loadings $>0.7$, Composite Reliability (CR): $\geq 0.7$, Average variance extracted (AVE): $\geq 0.5$, Rho_A coefficient: $>0.7$ (Hair et al., 2006); Discrimination value: The top coefficient is bigger than the correlation coefficients in the same column (Fornell - Larcker matrix coefficient); VIF $<5$; SRMR: < 0.082 (Henseler et al., 2010, 2012, 2015, 2016); (<0.12 acceptable); d_ULS: <95\%; ${ }^{2}, \mathrm{f}^{2}, \mathrm{Q}^{2}$ (Hair et al., 2016).

\section{Results}

Results of the reliability analysis show that all factors satisfy Cronbach's Alpha analysis conditions: Total correlation coefficient $>0.3$ Cronbach's Alpha value: $>0.7 ; \mathrm{KMO}=0.896$, Sig value $=0.00$ and Outer Loadings $>0.7$.

Next we evaluate the scale model with the following results:

Table 1

Construct Reliability and Validity

\begin{tabular}{lcccc}
\hline & Cronbach's Alpha & rho_A & $\begin{array}{c}\text { Composite Reli- } \\
\text { ability (CR) }\end{array}$ & $\begin{array}{c}\text { Average Variance Extracted } \\
\text { (AVE) }\end{array}$ \\
\hline Attitude & 0.898 & 0.900 & 0.899 & 0.640 \\
Behavioral intention & 0.981 & 0.981 & 0.981 & 0.668 \\
Knowledge Sharing Behavior & 0.866 & 0.872 & 0.867 & 0.567 \\
Perceived behavioral control & 0.918 & 0.919 & 0.918 & 0.693 \\
Subjective norms & 0.913 & 0.915 & 0.913 & 0.637 \\
\hline
\end{tabular}

It can be seen from Table 1 that all values of AVE $>0.5$; rho_A $>0.7$; Cronbach's Alpha $>0.7, \mathrm{CR}>0.7$, therefore, all potential variables satisfy conditions of Henseler et al. (2015). 
Table 2

Discriminant Validity

Fornell-Larcker Criterion

\begin{tabular}{|c|c|c|c|c|c|}
\hline & Attitude & $\begin{array}{c}\text { Behavioral } \\
\text { intention }\end{array}$ & Knowledge Sharing Behavior & $\begin{array}{c}\text { Perceived } \\
\text { behavioral control }\end{array}$ & Subjective norms \\
\hline Attitude & 0.800 & & & & \\
\hline Behavioral intention & 0.309 & 0.817 & & & \\
\hline Knowledge Sharing Behavior & 0.441 & 0.562 & 0.753 & & \\
\hline Perceived behavioral control & 0.577 & 0.220 & 0.368 & 0.832 & \\
\hline Subjective norms & 0.492 & 0.350 & 0.504 & 0.339 & 0.798 \\
\hline
\end{tabular}

According to Henseler et al (2015) if the top coefficients are greater than the correlation coefficients in the first column then it is satisfied. We can see from the results in Table 2 that research data is suitable to the requirements. All items have VIF $<$ 5, so there is no multicollinearity phenomenon, SRMR: $0.059<0.082$; d ULS $=86.9 \%<95 \%$. Therefore, the conditions of reliability, convergence and discrimination values of the study variables are consistent with the research data and eligible for further analysis.

Table 3

Model fit

\begin{tabular}{ccc}
\hline & Saturated Model & Estimated Model \\
\hline SRMR & 0.052 & 0.059 \\
d_ULS & 3.823 & 4.569 \\
d_G & 0.858 & 0.869 \\
Chi-Square & 695.126 & 798.526 \\
NFI & 0.862 & 0.881 \\
\hline
\end{tabular}

From the results of Table 3, it is shown that all values of SRMR, d_ULS, Chi-Square, d_G, NFI satisfy conditions, which proves that the research data is consistent with the research model. Next, we test the research hypotheses. Results are as follows:

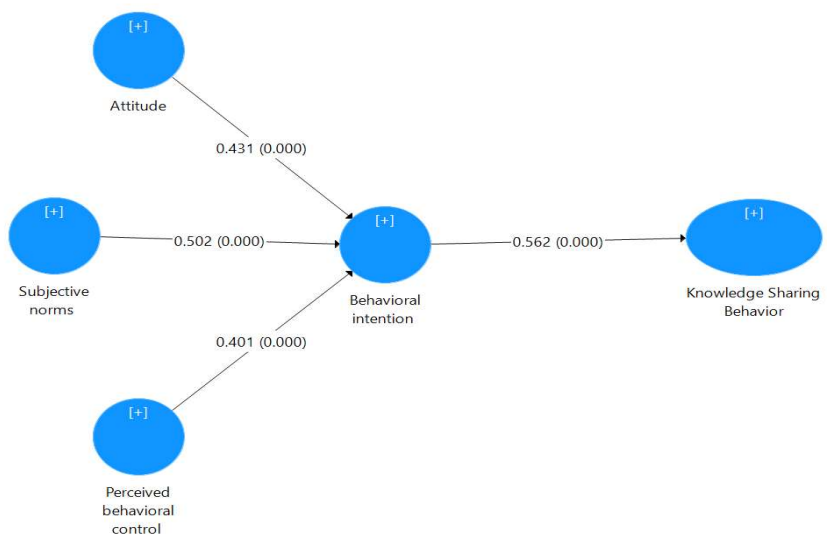

Fig. 2. Bootstrapping results (Smart PLS output)

We can see from the results in Fig. 2 that Attitude has a positive direct impact on Behavioral intention with a very strong level of 0.431 at significance level of $1 \%(\mathrm{P}$-value $=0.000)$, which means that the hypothesis $\mathrm{H}_{1}$ is supported. A positive attitude to knowledge sharing will strongly impact on the knowledge sharing intention of lawyers in the North of Vietnam. Subjective norms also have a positive direct impact on Behavioral intention with a very strong level of 0.502 at significance level of $1 \%$ ( $\mathrm{P}$-value $=0.000$ ), which means that the $\mathrm{H}_{2}$ hypothesis is supported, proving that the lawyers having a positive subjective judgment for their colleagues about the sharing of knowledge will highly intend to share knowledge. Perceived behavioral control directly positively affects Behavioral intention with a very strong level of 0.401 at the significance level of $1 \%$ (Pvalue $=0.000$ ), which means that the hypothesis $\mathrm{H}_{3}$ is supported; with lawyers controlling their behavior well, always positive, this factor has a very strong positive impact on the intention to share their knowledge. Lastly, Behavioral intention also has positive direct effect on Knowledge Sharing Behavior with a very strong level of 0.562 at significance level of $1 \%$ (P-value $=0.000)$, which means that the hypothesis $\mathrm{H}_{4}$ is supported, proving that most lawyers who intends to share their knowledge will likely have an act of knowledge sharing. 
To test the intermediary role of intention, we proceed in four steps (Hair et al., 2014).

Step 1: Intention has a direct, statistically significant effect on knowledge sharing behavior. The results are as follows:

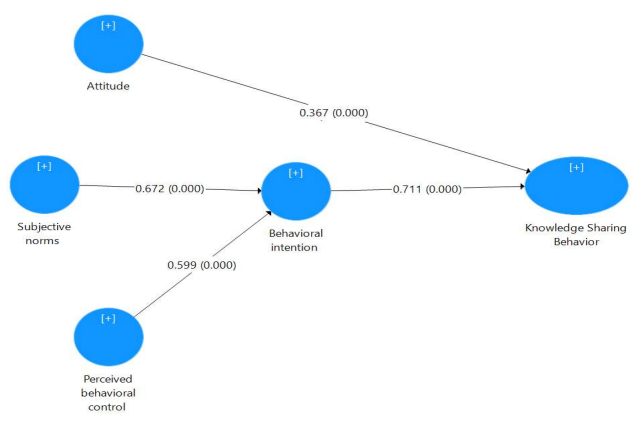

Fig. 3: Attitude impact directly Knowledge Sharing Behavior

Step 1 is satisfied, the intention has a strong positive direct impact at a statistically significant level on the lawyers' knowledge sharing behavior $(\beta=0.367, \mathrm{P}=0.000)$. Step 2,3 shown in Fig. 2 are satisfied (hypotheses $\mathrm{H}_{1}$ and $\mathrm{H}_{4}$ are statistically significant).

Step 4: Testing the intermediary role in the overall model as follows:

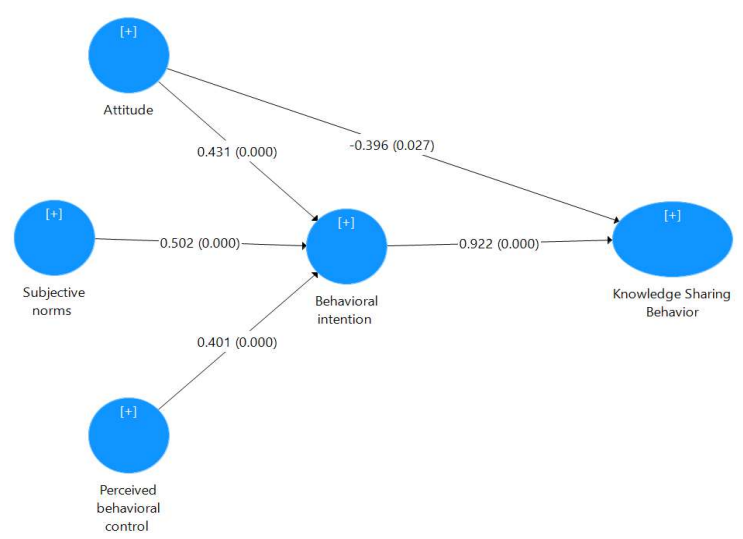

Fig. 4. Mediate role of Behavioral intention

We can see from the results of Fig. 4 that in the overall SEM model, intention no longer has a statistically significant impact on the knowledge sharing behavior of lawyers. Therefore, the intention has a comprehensive intermediary role in the relationship between attitudes and knowledge sharing behavior of lawyers in the North of Vietnam. This means that the $\mathrm{H}_{5}$ hypothesis is supported. Finally, we examine the moderator role of information technology usage in the relationship between intention and knowledge sharing behavior of lawyers in the North of Vietnam. The results are as follows:

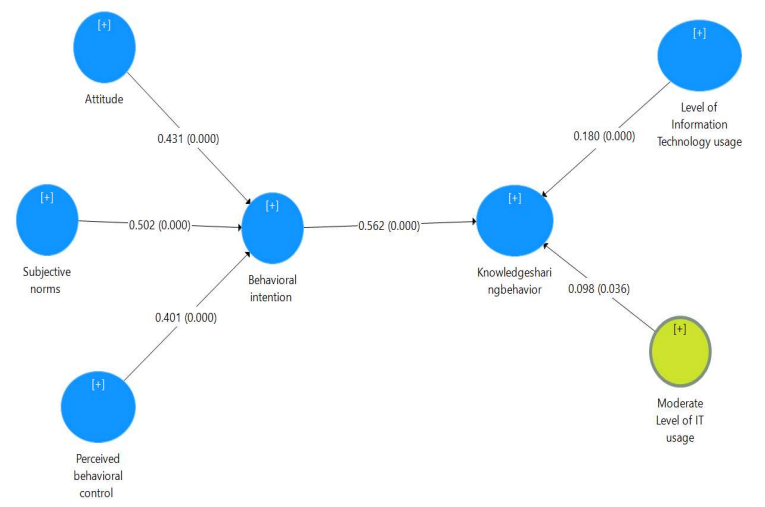

Fig. 5. Moderate role of Level of IT usage 
From the results of Fig. 5, it can be seen that the level of information technology usage does not play a role in moderating the impact of knowledge sharing intention on the knowledge sharing behavior of lawyers in the North of Vietnam.

In the overall research model, the coefficient $\mathrm{R}^{2}$ is $53.2 \%$, which means that the variables in the model explain $53.2 \%$ of the variation in knowledge sharing behavior of lawyers in the North of Vietnam. Additionally, the $\mathrm{f}^{2}$ and $\mathrm{Q}^{2}$ coefficients are at average levels $(0.157$ and 0.182$)$.

\section{Conclusions}

After carefully conducted, the research introduces factors including attitude, subjective norms, and perceived behavioral control that have very strong direct positive impacts on the behavioral intention to share knowledge of lawyers in the North of Vietnam. The behavioral intention at the same time has a strong impact on the knowledge sharing behavior of the lawyers. This study further strengthens the theory of planned behavior of Ajzen and Fishbein (2005). Moreover, this study supports the findings of previous studies in different contexts, different areas and different economies such as studies by Mehrabi et al. (2013), Mafabi et al. (2017), Al-Alawi (2005), Al-Alawi et al. (2007), Skyrme (2008), Lin (2007), Zihidul et al. (2011), Wei et al. (2012), Mansor and Kenny (2013) and Bui (2014). However, the factor of the level of information technology usage does not play a role on moderating the impact of intention on the knowledge sharing behavior of lawyers in the North of Vietnam, this result is contrary to the results in the study by $\mathrm{Wu}$ and $\mathrm{Zhu}$ (2012) studying knowledge sharing behavior of lawyers in Nigeria. This is because in the context of Vietnam, although information technology has been highly developed, the culture of knowledge sharing via social networks has not been popular, consequently, the level of information technology usage does not have a statistically significant moderator role in the relationship between intention and behavior of knowledge sharing of lawyers from the North of Vietnam.

The profession of lawyer around the world is organized in many forms and diversified. This diversity stems from the unique characteristics of history, culture, way of thinking as well as the legal system of each country. Despite many different points of view on the profession of lawyer, there is a common point that lawyer is a profession in the society, an effective tool to ensure justice. The profession of lawyer appreciates individual roles, professional reputation of lawyers and the nature of the freelance profession in the law-practicing organization. Particularly, the profession of lawyer highly values the acquired knowledge of lawyers. For the purpose of enhancing knowledge of lawyers, knowledge sharing is essential to help lawyers in the North of Vietnam in particular and lawyers around the world in general have profound knowledge and create core competitive advantages for law offices and law firms.

\section{References}

Ajzen, I., \& Fishbein, M. (2005). The influence of attitudes on behavior. The handbook of attitudes, 173(221), 31.

Al-Alawi, A.I. (2005). The practice and challenges of knowledge management in financial sectors in Bahrain. Asian Journal of Information Systems, 4(1), 101-107.

Al-Alawi, A.I., Al-Marzooqi, N.Y., \& Mohammed, Y.S. (2007). Organizational culture and knowledge sharing: critical success factors. Journal of Knowledge Management, 11(2), 22-42.

Alavi, M., Kayworth, T.R., \& Leidner, D. (2005). An empirical examination of the influence of organizational culture on knowledge management practices. Journal of Management Information Systems, 22, 191-224.

Asiegbu, F.B. and Iruka, C. (2012). Consumer attitude: some reflections on its concept, trilogy, relationship with consumer behavior, and marketing implications. European Journal of Businessand Management, 4(13), 38-50.

Bhatti, K.L., Latif, S. and Rao, N.I. (2014). Knowledge sharing intentions in doctors of private and government hospitals. Issues in Business Management and Economics, 2(8), 128-133.

Bui, T. T. (2014). Factors affecting knowledge-sharing behavior with lecturers of university lecturers. Journal of Economics and Development, 199, $71-79$.

Chennamaneni, A., Teng, J.T.C. \& Raja, M.K. (2012). A unified model of knowledge sharing behaviours: theoretical development and empirical test. Behaviour \& Information Technology, 31(11), 1097-1115.

Davenport, T. \& Prusak, L. (1998). Working knowledge: How organizations manage what they know? Harvard Business School Press.

Gebretsadik, T., Mirutse, G., Tadesse, K. \& Terefe, W. (2014). Knowledge sharing practice and its associated factors of healthcare professionals of public hospitals, Mekelle, Northern Ethiopia. American Journal of Health Research, 2(5), 241246.

Gottschalk, P., Brekke, K. \& Pedersen, H.C., (2005). Incentives for Knowledge Sharing through Information Technology in Law Firms' in Virtual Law Journal, viewed 17 February 2011, from http://www.virtuallawjournal.net/?nodeid=32\&lang=en

Hair, J., Black, B., Babin, B., Anderson, R. \& Tatham, R. (2006). Multivariate Data Analysis, 6th ed., Prentice-Hall, Upper Saddle River, NJ.

Hair Jr, J., Sarstedt, M., Hopkins, L., \& G. Kuppelwieser, V. (2014). Partial least squares structural equation modeling (PLSSEM) An emerging tool in business research. European Business Review, 26(2), 106-121.

Hair, J. F., Hult, G. T. M., Ringle, C. M., \& Sarstedt, M. (2013). A Primer on Partial Least Squares Structural Equation Modeling (PLS-SEM). Thousand Oaks: Sage. 
Henseler, J., \& Chin, W. W. (2010). A comparison of approaches for the analysis of interaction effects between latent variables using partial least squares path modeling. Structural Equation Modeling, 17(1), 82-109.

Henseler, J., Hubona, G., \& Ray, P. A. (2016). Using PLS path modeling in new technology research: updated guidelines. Industrial Management \& Data Systems, 116(1), 2-20.

Henseler, J., Ringle, C. M., \& Sarstedt, M. (2015). A new criterion for assessing discriminant validity in variance-based structural equation modeling. Journal of the Academy of Marketing Science, 43(1), 115-135.

Henseler, J., Ringle, C. M., \& Sarstedt, M. (2012). Using partial least squares path modeling in advertising research: basic concepts and recent issues. In S. Okazaki (Ed.) Handbook of research on international advertising, 252-276. Edward Elgar.

Hendriks, P. (1999). Why share knowledge? The influence of ICT on the motivation for knowledge sharing. Knowledge and Process Management, 6(2), 91-100

Hlupic, V., Pouloudi, A. and Rzevski, G. (2002). Towards an integrated approach to knowledge management: 'hard,' 'soft' and 'abstract' issues. Knowledge and Process Management, 9(2), 90-102.

Ipe, M. (2003). Knowledge aharing in organisations: a conceptual framework. Human Resource Development Review, 2(4), 337-359.

Kimiz, D. (2005). Knowledge Management in Theory and Practice. Montreal: McGill University Press

Kukko, M. (2013). Knowledge sharing barriers in organic growth: a case study from a software company. The Journal of High Technology Management Research, 24(1), 18-29.

Lee, H. and Choi, B. (2003). Knowledge management enablers, processes, and organizational performance: an integrative view and empirical examination. Journal of Management Information Systems, 20(1), 179-228.

Lin, H. F. and Lee, G.-G. (2004). Perceptions of senior managers toward knowledge-sharing behavior. Management Decision, $42(1), 108-125$.

Lin, H.F. (2007). Knowledge sharing and firm innovation capability: an empirical study. International Journal of Manpower, 28(3/4), 315-332.

Mafabi, S., Nasiima, S., Muhimbise, E. M., M. \& Kasekende, F. (2017). The mediation role of intention in knowledge sharing behavior. VINE Journal of Information and Knowledge Management Systems, 47(2), 172-193.

Markus, M.L. (2001). Towards a theory of knowledge reuse: types of knowledge reuse situations and factors in reuse success. Journal of Management Information Systems, 18(1), 57-94.

Mehrabi, S., Siyadat, S. \& Allameh, S. (2013). Studying the Relationship between the Process of Knowledge Sharing and Organizational Agility among personnel of Agriculture - Jahad Organization in Share-Kord. International Journal of Academic Research in Business and Social Sciences, 3(5), 324-36.

Nonaka, I. (1994). A dynamic theory of organizational knowledge creation. Organizational Science, 5(1), 14-37.

Nonaka, I. \& Takeuchi, H. (1995). The Knowledge Creating Company, Oxford University Press, Oxford.

Nonaka, I., \& Takeuchi, H. (1996). A theory of organizational knowledge creation. International Journal of Technology Management: Special publication on unlearning and learning, 11(7), 833-845.

Oliver, S., \& Kandadi, K. R. (2006). How to develop knowledge culture in organizations? A multiple case study of large distributed organizations. Journal of Knowledge Management, 10, 6-24.

Ojo, R.R. \& Grand, B., (2011). An Analysis of the Extent of IT Acceptance and Use for Knowledge Management in Botswana Law Organizations, Infotrends: An International Journal of Information and Knowledge Management, 1(1), $27-37$.

Perrot, B.E. (2007). A strategic risk approach to knowledge management. Business Horizons, 50, 523-33.

Senge, P., (2007). On sharing knowledge. The Gurteen Knowledge, viewed 14 November 2010, from http://www.gurteen.com/gurteen/gurteen.nsf/id/X00035A9E/

Swart, J. \& Kinnie, N. (2003). Sharing knowledge in knowledge-intensive firms. Human Resource Management Journal, 13(2), 60-75.

Skyrme, D. J. (2008). The 3Cs of Knowledge Sharing: Culture, Co-opetition and Commitment, 64, 1-6.

Wei, C., The, P., \&Asmawi, A. (March 2012). Knowledge Sharing Practices In Malaysian MSC Status Companies. Journal of Knowledge Management Practice, 13(1), 23 - 38.

Wu, Y. \& Zhu, W. (2012). An integrated theoretical model for determinants of knowledge sharing behaviours. Kybernetes, $41(10), 1462-1482$.

Zawawi, A.A., Zakaria, Z., Kamarunzaman, N.Z., Noordin, N., Sawal, M.Z.H.M., Junos, N.M. and Najid, N.S.A.N. (2011). The study of barrier factors in knowledge sharing: a case study in public university. Management Science and Engineering, 5(1), 59-70.

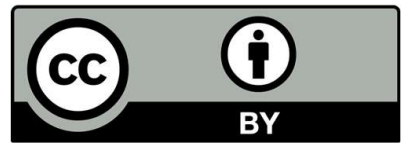

(C) 2020 by the authors; licensee Growing Science, Canada. This is an open access article distributed under the terms and conditions of the Creative Commons Attribution (CC-BY) license (http://creativecommons.org/licenses/by/4.0/). 